\title{
LENIN E OS PARTIDOS COMUNISTAS ALEMÃES
}

\author{
LENIN Y LOS PARTIDOS COMUNISTAS ALEMANES
}

\section{LENIN AND THE GERMAN COMMUNIST PARTIES}

DOI: http://dx.doi.org/10.9771/gmed.v12i2.37714

Túlio César Dias Lopes ${ }^{1}$

Resumo: O Movimento Comunista Internacional (MCI) teve na Alemanha uma história marcada por intensos embates teóricos, políticos e sociais. Destacamos neste trabalho alguns elementos e informações acerca da História dos Partidos Comunistas na Alemanha, destacando em especial a trajetória da atuação do Partido Comunista da Alemanha (KPD), desde sua fundação até a reconstituição do Partido Comunista na Alemanha nos dias atuais atuando com a nomenclatura de Partido Comunista Alemão (DKP). Neste trabalho procuramos apresentar as principais formações políticas partidárias oriundas do KPD, a rejeição e os vínculos (mesmo que formais) com a concepção leninista de organização.

Palavras-chaves: Partido Comunista. Internacional. Leninismo. Esquerdismo. Revolução.

Resumen: El Movimiento Comunista Internacional (MCI) tuvo una historia en Alemania marcada por intensos enfrentamientos teóricos, políticos y sociales. Destacamos en este trabajo algunos elementos e información sobre la historia de los partidos comunistas en Alemania, destacando en particular la trayectoria de la actuación del Partido Comunista de Alemania (KPD), desde su fundación hasta la reconstitución del Partido Comunista en Alemania hoy, actuando con la nomenclatura del Partido Comunista Alemán (DKP). En este trabajo tratamos de presentar las principales formaciones de partidos políticos que se originan en el KPD, el rechazo y los vínculos (incluso si son formales) con la concepción leninista de la organización.

Palabras clave: Partido Comunista. Internacional. Leninismo. Izquierda. Revolución.

Abstract: The International Communist Movement (ICM) had in Germany a history marked by intense theoretical, political and social conflicts. In this paper a few elements and information on the History of Germany's Communist Parties are highlighted, in special the action trajectory of The Communist Party of Germany (KPD), from it's creation to it's reconstitution nowadays acting as The German Communist Party (DKP). In this paper we seek to present major political parties that came from KPD, rejection and bonds (even formals) with the Leninist conception of organization.

Keywords: Communist Party. International. Leninism. Leftism. Revolution.

\section{Introdução}

A luta dos comunistas alemães pela Revolução Alemã teve como auge a período revolucionário que se abre após a primeira guerra mundial e teve forte influência da Revolução Russa de outubro de 1917. Neste período marcado por uma situação revolucionária ocorreram diversas tentativas insurrecionais na Alemanha. Desde a formação da II Internacional em 1889, a Alemanha se converteu no centro nevrálgico do Movimento Operário Internacional tendo o maior e principal partido operário, o Partido Social-Democrata Alemão (SPD). Os marxistas revolucionários tais como Rosa Luxemburgo, Karl Liebknecht e Clara Zetkin, entre outros, atuaram 
neste Partido rompendo depois que o SPD apoiou a participação da Alemanha na Guerra. Os principais revolucionários alemães convergiram na construção e formação do Partido Comunista da Alemanha (KPD).

O Partido Comunista da Alemanha (KPD) foi fundado em dezembro de 1918 a partir da fusão entre a Liga Spartakus e outras correntes oriundas principalmente do Partido Social Democrata Independente (USPD). Após a ruptura com a Socialdemocracia Alemã em 1916, é formada a Liga Spartakus. Rosa Luxemburgo ao se referir a Liga Spartakus destaca que lhe caberia uma tarefa especial na Revolução Alemã e que "Os spartakistas abriram caminho para uma tática nova e revolucionária, a da ação de massas extraparlamentar, exortaram e chamaram incansavelmente à greve de massas até conseguirem fortalecer e elevar a autoconfiança, a coragem do operariado para a luta. (2018: p.331-332). A Liga Spartakus cumpriu este papel especial ao criar as condições para a formação de um novo Partido Revolucionário.

Analisando os processos revolucionários Rosa Luxemburgo destaca o papel da Liga "ser essa bússola que aponta a direção, essa flecha que se move para diante, o fermento proletáriosocialista da revolução - eis a tarefa específica da Liga Spartakus no embate atual entre dois mundos. A História é a única mestra verdadeira e a revolução é a melhor escola para o proletariado”. (2018: p.332-333). Rosa atribui a organização um papel de bússola que aponta a direção revolucionária e afirma que a melhor escola para o proletariado é a Revolução.

O KPD teve ao longo de sua história diversas dissidências, fusões, dissolveu-se e se reconstituiu com a formação do Partido Comunista Alemão (DKP). Ao incorporar-se à Internacional Comunista (1919-1943) o KPD consolida-se como um Partido Comunista de orientação Marxista-Leninista. O KPD no período entre a sua fundação e seu esfacelamento pela ditadura hitlerista tornou-se uma das principais forças políticas e sociais da Alemanha, sendo considerado o principal inimigo político do Nazismo e o mais empenhado em combatê-lo. Neste trabalho procuramos apresentar as principais formações políticas partidárias oriundas do KPD e o vínculo político (mesmo que formal) com a concepção leninista de organização.

\section{Lenin e o Partido Comunista da Alemanha (KPD)}

Desde os tempos da Segunda Internacional Lenin manteve relações políticas com os revolucionários alemães e manteve sua perspectiva em relação a possibilidade histórica de uma Revolução na Alemanha, onde a organização e luta do proletariado estava mais avançada. Lênin por contribuiu a partir da Rússia na construção de um partido revolucionário integrado a luta do proletariado capaz de fazer avançar a luta revolucionária pelo Socialismo na perspectiva do Comunismo. Lenin após liderar a Revolução Russa de 1917, volta a sua atenção para as tentativas de Revolução na Alemanha, Polônia e Hungria e articula a criação da Internacional Comunista em 1919, congregando diversas organizações revolucionárias. 
Lezcano destaca que "as consequências da derrota na Primeira Guerra Mundial e a influência da Revolução de Outubro provocaram uma situação sumamente complexa na Alemanha" (2008, p.150), nos informando em seguida que:

Por um lado, a revolução de novembro de 1918 foi capitalizada pela socialdemocracia de direita, que a conduziu a um regime republicano, o de Weimar, apenas tolerado pela direita tradicional - somente na medida em que salvou o sistema - e criticado tanto pela extrema direita, que o considerava responsável pela situação do país, como pela esquerda - agrupada no Partido Comunista desde janeiro de 1919 -, que o via como o resultado da frustração da revolução e como responsável do assassinato de líderes como Karl Liebknecht e Rosa Luxemburgo. Por outro lado, a imposição do Tratado de Versalhes representou uma pesada carga para o povo alemão e feriu profundamente seu sentimento nacional. Tudo isso conduziu a um clima de instabilidade econômica, política e social, que com altas e baixas se prolongou até 1923. (LEZCANO, 2008, p.150)

$\mathrm{Na}$ Alemanha Rosa Luxemburgo foi uma das principais lideranças revolucionárias fomentando o debate político, socioeconômico e filosófico referenciado no marxismo e participando ativamente das lutas do período. Mesmo sendo brutalmente assassinada em 1919, sua referência extrapolou os limites político-organizativos de seu agrupamento político impactando diretamente na luta dos trabalhadores alemães pela revolução. Rosa Luxemburgo (2018, p.372) destaca que o Partido Comunista da Alemanha (KPD) nasce buscando dar "uma enérgica orientação à esquerda" para a massa dos trabalhadores e soldados buscando "a unificação de todos os elementos verdadeiramente proletários e revolucionários num quadro organizativo". Considerado o espaço “onde a luta revolucionária encontrou sua expressão mais clara e decidida”.

Cabe destacar os intensos e ricos debates de Lenin e Rosa Luxemburgo, entre outras coisas, sobre a concepção de partido e dinâmica dos trabalhos partidários, a discordância em relação às medidas políticas adotadas pelos bolcheviques no processo revolucionário russo, como a dissolução da Assembleia Constituinte, a discussão sobre a questão nacional e o Imperialismo. E, considerar os principais elementos convergentes que também merecem destaque e atenção tais como : o vínculo com a teoria revolucionária marxiana, a compreensão da necessidade de formação de um Partido Revolucionário, a luta pela formação de uma Internacional Proletária, a busca pela construção do Poder Proletário a partir dos Conselhos, a participação com independência política nas lutas políticas eleitorais e o objetivo final da Revolução Socialista na perspectiva do Comunismo.

O Partido Comunista da Alemanha (KPD) ingressa desde sua fundação na Internacional Comunista, aceitando suas condições. Um primeiro momento, sua fundação a partir da fusão da Liga Spartakus e da ala esquerda do Partido Social-democrata independente da Alemanha (USPD). O segundo momento, marcado pela luta interna entre os "comunistas de Esquerda" e os comunistas mais alinhados ao PCUS e a Internacional Comunista. O terceiro, marcado pela expulsão dos "comunistas de esquerda" e pela caracterização da social democracia alemã como "social-fascistas". E, um quarto momento marcado pelas ações antifascistas, crescimento político eleitoral dos comunistas alemães e a tentativa de formação de uma Frente Única com os 
Artigos

trabalhadores sociais-democratas do SPD (1928-1932). A quinta fase é marcada pela resistência ao fascismo hitlerista (1933-1945).

Um forte embate interno no KPD estremeceu as relações com a Internacional Comunista no início dos anos vinte. Este embate se deu principalmente em relação a três questões: a participação nas eleições parlamentares, a questão sindical e as insurreições armadas. em seu artigo "O Comunismo de Esquerda" destaca que "em abril de 1920, Lenin expressou a convicção de que a iminência da revolução mundial justificava a esperança "numa rápida e perfeita cura do movimento comunista internacional da doença infantil do comunismo 'de esquerda'”.

Lenin destacou uma série de críticas a postura negativa e abstencionistas de alguns partidos comunistas europeus (notadamente o KPD) em sua época e cunhou uma expressão característica destes agrupamentos, o esquerdismo. Pouco tempo antes, Rosa Luxemburgo já destacava o papel educativo das eleições para as massas proletárias:

Precisamos educar as massas no espírito de nossa tática, para que saibam utilizar o instrumento das eleições não como uma arma da contrarrevolução, mas como massas com consciência de classe, revolucionárias, para aniquilar, com a mesma arma aqueles que a empurraram para as nossas ações. [...] Nossa tática leva em conta as próximas tarefas ligadas às tarefas da iminente revolução como um todo, até que as massas proletárias alemãs estejam maduras para segurar as rédeas. $(2018$, p.340)

Ressaltava a necessidade de amadurecer as massas proletárias alemãs por meio do revolucionamento intelectual das massas e da educação no espírito da tática utilizando por exemplo as eleições para a Assembleia Nacional. Rosa refere-se à Assembleia Nacional como a possibilidade de uma "nova escola para a educação da classe". Na luta pelo poder a educação do proletariado é vital para o processo revolucionário e a melhor escola é a luta de classes.

Lenin trava uma batalha teórica com sérias consequências políticas com os Comunistas "de esquerda" alemães. A análise sobre esta questão feita pelos comunistas “de esquerda" alemães é apontada como insuficiente, devido a três fatores. Primeiro, que os "esquerdas" alemães, como é sabido, consideravam já em janeiro de 1919 que o parlamentarismo estava "politicamente caduco", a despeito da opinião de dirigentes políticos tão destacados como Rosa Luxemburgo e Karl Liebknecht que haviam pronunciado a favor da participação nas eleições e provaram a necessidade de utilizar a tribuna parlamentar para popularizar as palavras de ordem revolucionárias entre as massas. Diante deste e outros enganos cometidos pelos comunistas de "esquerda" alemães, que na avaliação de Lenin ainda não se configuravam como um Partido Revolucionário, o líder revolucionário russo chama a atenção para o processo de crítica e autocrítica necessário na construção de um partido revolucionário.

A atitude de um partido político perante os seus erros é um dos critérios mais importantes e mais seguros da seriedade do partido e do cumprimento de facto por ele das suas obrigações para com a sua classe e para com as massas trabalhadoras. Reconhecer abertamente o erro, por a descoberto as suas causas, analisar a situação que o engendrou e discutir atentamente os meios de corrigir o erro - isto é o indício de um partido sério, isto é o cumprimento por ele das 

suas obrigações, isto educar e instruir a classe, e depois também as massas. (LENIN, 1986. p.37-38).

Segundo, Lenin (p.38) aponta que o discurso do grupo dos “esquerdas” alemães é contraditório pois “é evidente que o parlamentarismo na Alemanha ainda não está politicamente caduco. É evidente que os "esquerdas" da Alemanha tomaram o seu desejo, a sua atitude políticoideológica, pela realidade objetiva. Este é um erro perigosíssimo para os revolucionários". Afirmando a obrigatoriedade da participação nas eleições parlamentares e a necessidade de utilizar a tribuna parlamentar que "para o partido do proletariado revolucionário precisamente para educar as camadas atrasadas de sua própria classe, precisamente para despertar e instruir a massa rural não desenvolvida, embrutecida e ignorante”. (LENIN, 1986, p.39)

Terceiro, Lenin destaca a questão tática da participação no parlamento democrático burguês tendo em vista a estratégia revolucionária "as amplas massas dos trabalhadores estão preparadas (ideológica, política e praticamente) para aceitar o regime soviético e dissolver (ou permitir a dissolução) o parlamento democrático-burguês”. (LENIN, 1986. p.40) Outro elemento que Lenin critica é a negação por parte dos Comunistas de "esquerda" da necessidade do Partido e da disciplina partidária, contribuindo para "desarmar completamente o proletariado, em proveito da burguesia". Segundo Lenin "Negar a necessidade do Partido, do ponto de vista do comunismo, é dar um salto das vésperas da derrocada do capitalismo (na Alemanha) não até a fase inferior ou média do comunismo, mas até a sua fase superior”. (LENIN, 1986, p.40)

Destas polêmicas em relação a participação nas eleições parlamentares, nos sindicatos reformistas (e até nos reacionários), da disciplina partidária e da política de alianças, nasce a primeira divisão no KPD, que congregou os Comunistas de Esquerda e que culminou na formação do Partido Comunista Operário Alemão (KAPD). Esta política ultra esquerdista contribuiu para a dispersão do Movimento Comunista na Alemanha, enfraquecendo seu principal partido, dividindo o movimento sindical e pautando a abstenção no período de acirramento da luta de classes e da polarização política marcado pela ascensão do nazismo. Sob a liderança de Adolf Hitler (18891945), o Partido Operário Nacional Socialista Alemão (Nazi) “foi se desenvolvendo pouco a pouco, especialmente na Baviera, onde recebeu o apoio de importantes empresários e latifundiários". (LEZCANO, 2008, p.151)

Cabe destacar que, segundo Lezcano (2008, p.151) "A medida que foi aumentando a influência do Partido Comunista, o objetivo principal da propaganda nacional-socialista foi a denuncia do bolchevismo, apresentado como uma conspiração internacional de financeiros judeus". A Alemanha passava por "uma profunda crise política e social somente comparável com a gerada pela Guerra”. Neste período:

Cresceu rapidamente a influência dos comunistas, que se converteram em um partido de massas. O país foi estremecido por numerosas e massivas greves. Em Sajonia e Turingia foram criados governos operários, a partir da unidade de comunistas e socialdemocratas de esquerda. Em alguns lugares aconteceram insurreições, como ocorreu em Hamburgo, onde se destacou a figura de Ernest 
Thaelmann², futuro secretário do Partido Comunista. Paralelamente cresceu a onda ultranacionalista. (2008, p.152)

Em dezembro de 1922 Clara Zetkin³ apresenta, em dezembro de 1922, em seu texto “O Governo dos Trabalhadores" as suas "Teses do Governo Operário" na perspectiva de construção da Frente Única Proletária. Segundo Clara Zetkin:

O Governo Operário é a tentativa de forçar o Estado burguês no marco de suas limitações históricas essenciais, para servir aos interesses históricos do proletariado. [...] Neste momento histórico, uma verdadeira política operária deve ser uma política revolucionaria, a mais aguda política de luta contra a burguesia, orientada a reforçar o poder do proletariado. [...] certos fatores devem ser decisivos: a limpeza no rosto que representa o Partido Comunista; a independência da política comunista; os fortes laços com as massas; uma orientação para aprofundar e acelerar o processo de tomada de consciência pela classe operária e, por fim, o crescimento de seu poder.

Em 1920, o KPD recém-fundado obtém 589.454 votos (2,1\%) elegendo 4 deputados (4/459) nas eleições parlamentares ficando em "oitavo lugar". Após as tentativas de insurreição nos primeiros anos dos anos 20 o KPD obtém um extraordinário crescimento político-eleitoral, em maio de 1924, obtém 3.693.280 votos (12,6\%) e 62 deputados/as (62/472), configurando-se como a quarta força política do país. Clara Zetkin chegou a ser pré-candidata à Presidência da República pelo KPD sendo substituída por Thälmann outra liderança do Partido Comunista Alemão “em 1923, a direção do KPD decidiu propor o nome de Clara para as eleições presidenciais. Em 1924, voltou atrás e designou Thälmann que, no ínterim, tornara-se o homem de confiança do Komintern” (BADIA, 2003, p.274). Mesmo com as dissidências internas o KPD mantém-se nas eleições de 1928 na quarta posição obtendo 3.264 .793 votos (10,6\%) e 54 deputados/as (54/491) permaneceram enquanto oposição ao governo Social-democrata da República de Weimar (19191933). Em 1930, o KPD se torna a terceira força política alemã, alcançando 4.590 .160 votos $(13,1 \%)$ e 77 deputados/as $(77 / 577)$ continuando na oposição, rejeitando e sendo rejeitado pelo SPD. E, em novembro de 1932, os comunistas atingem seu auge político com 5.980.614 votos $(16,9 \%)$ e 100 deputados (100/584).

Em 30 de janeiro de 1933, os nazistas marcham com suas tochas pelo Portão de Brandemburgo. Em fevereiro, ocorre um incêndio no Reichstag que é atribuído pela imprensa burguesa aos comunistas buscando criminaliza-los. Claramente não era essa a tática dos comunistas do KPD no período. Hitler apresenta uma falsa acusação aos comunistas, e os nazistas tendo os comunistas como inimigos principais desencadeiam uma repressão implacável contra Partido Comunista da Alemanha (KPD), principal partido de oposição a Hitler.

Em 30 de Janeiro de 1933 Hitler é nomeado chanceler do Reich pelo presidente Hindenburg. Em 27 de Fevereiro, culpa os comunistas pelo incêndio do Reichstag. Em Março, o Parlamento vota a favor de plenos poderes para Hitler. O Partido Comunista da Alemanha (DKP) entra na clandestinidade. Nas eleições de 1933, mesmo em um contexto de fascistização e fortecampanha anticomunista o KPD, sob a liderança de Ernst Thälmann ${ }^{4}$ mantém-se como a terceira força com 4.848.058 votos $(12,3 \%)$ e 81 deputados (81/647). Nestas eleições, o Partido Nazista 
vence e ampliar uma a forte perseguição contra os comunistas. Já em 08 de março de 1933, foram cassados os mandatos dos deputados comunistas e militantes e dirigentes foram presos e perseguidos. Em 15 de março de 1933, o Partido foi declarado totalmente ilegal. Em maio são dissolvidos os sindicatos.

A ditadura nazista só foi derrubada após ter arrastado a Alemanha e o mundo para a $\mathrm{II}^{\mathrm{a}}$ Guerra mundial. Os primeiros campos de concentração foram feitos para os comunistas alemães. Durante o período da ditadura nazista na Alemanha o KPD foi esmagado, tendo diversos militantes e dirigente mortos em campos de concentração nazista. Os comunistas sofreram duramente com o fascismo hitlerista (1933-1945) atuando junto com outros grupos antifascistas na resistência Alemã.

Lezcano ao analisar o nacional-socialismo (nazismo) alemão destaca:

Independentemente da essência comum do fascismo, este apresenta em cada país certas características e rasgos próprios, que são determinados pelas particularidades do desenvolvimento histórico. O nacional-socialismo tinha muitos pontos em comum com o fascismo italiano, mas suas raízes eram tipicamente alemães: o autoritarismo e a expansão militar próprios da herança prussiana; a tradição romântica alemã que se oponha ao racionalismo, ao liberalismo e a democracia; diversas doutrinas racistas segundo as quais os povos nórdicos - o- chamados arianos puros - não só eram fisicamente superiores a outras raças, como também eram sua cultura e sua moral; assim como determinadas doutrinas filosóficas, especialmente a de Friedrich Nietzsche, que idealizaram ao Estado o exaltavam o culto a indivíduos superiores, ao que se eximiam de acatar as limitações convencionais". (2008, p.148)

Lezcano destaca o anticomunismo dos social-democratas e a desunião da social e democracia dos comunistas (KPD) nos informando que:

Ambos partidos representavam a fins de 1932, a maior força política do país; unidos haveria significado um obstáculo praticamente intransponível ante as aspirações da reação, mas permaneciam enfrentados, sem encontrar uma linguagem comum. Nisso foi determinante o feroz anticomunismo da socialdemocracia, que preferiu a Hitler antes uma saída revolucionária (2008, p.156)

Três questões polêmicas deste período merecem atenção e um debate aprofundado: o processo de bolchevização do KPD, o balanço crítico de Trotsky sobre a Revolução Alemã e o pacto germano-soviético. Todavia considero ser fundamental aprofundarmos o debate sem desconsiderar à luta e o heroísmo dos comunistas alemães do KPD.

\section{Os comunistas alemães do período pós-segunda guerra mundial até os dias atuais}

Após a libertação da Alemanha da ditadura hitlerista formou-se dois estados, a República Democrática Alemã (RDA) e a República Federal Alemã (RFA) mantendo a existência de Berlim Ocidental, encravada no território da RDA. O socialismo foi construído em um estado (a DDR) e o capitalismo (e o imperialismo) foi restaurado em outro (a RFA).

Em seu artigo "Não" às tradições do imperialismo alemão, Herbert Mies, então Presidente do Partido Comunista Alemão (DKP) destaca que "A derrota do fascismo hitlerista teve 
um impacto especial sobre a história alemã. O imperialismo alemão perdeu sua esfera de domínio anterior. Ao lado do Estado Capitalista alemão houve o surgimento do Estado Socialista Alemão" (1985, p.47). Destaca também que "A autêntica catástrofe nacional foi o triunfo do fascismo, foi o fato das forças de paz do povo alemão e de outros povos europeus não conseguirem prevenir a segunda guerra mundial" (p.48). O 08 de maio de 1945 significa para os comunistas alemães o "dia da libertação do jugo fascista e a conclusão de que a terra alemã jamais deverá voltar a envolver-se numa guerra” (p.49), em outras palavras, o dia da paz e da libertação. Enquanto que para a direita alemã “o 08 de maio foi o dia da capitulação alemã, o ponto baixo de nossa história” nas palavras do democrata cristão Kohl.

Mies destaca também que:

Nós, comunistas, rechaçamos a tese da "culta coletiva do povo alemão", que é falsa, pois com ela se retira a questão da responsabilidade bem concreta do grande capital, pai do fascismo e da guerra, e faz-se caso omisso de que a Alemanha em 1933-45 não era só um país de nazistas, mas também de antifascistas, dos quais dezenas de milhares tombaram na luta contra Hitler e seu bando (1985, p.53)

Boris Ponomariov em seu artigo A transcendência internacional da vitória da URSS na Grande

Guerra destaca:

Em maio de 1945, o povo soviético obteve uma grande vitória histórica na Grande Guerra Pátria contra os agressores e avassaladores hitleristas. Poucos meses depois, depôs as armas o Japão militarista, que tinha entrado em guerra ao lado da Alemanha hitlerista em dezembro de 1941, com a agressão aos Estados Unidos e Grã-Bretanha. A derrota e a capitulação incondicional da Alemanha fascista e seu aliado japonês mostrou o caráter quimérico, irrealizável, dos que pretendiam, mediante o desencadeamento de uma guerra mundial, estabelecer o domínio sobre os povos do mundo para subjuga-los e impor à humanidade o selvagem regime fascista. (1985, p.57)

Cabe destacar que a "Alemanha perdeu na Frente Oriental 75\% de todo o material bélico de que dispunha”. E, “A grande vitória do Exército Soviético foi um dos mais importantes fatores internacionais que contribuíram para que se iniciasse a formação do sistema mundial do socialismo, da comunidade socialista dos Estados”. (LEZSCANO, 2008, p.59) Outra questão importante destacada pelo historiador cubano foi que "Em resultado da missão libertadora da União Soviética, os povos de vários países puderam expressar sua vontade de modo autenticamente livre, o que abriu caminho para o estabelecimento do regime da democracia popular, para a edificação do socialismo" (LEZSCANO, 2008, p.59).

Lezcano destaca que:

Em março de 1952, quando se preparava o rearme germanoocidental, a URSS propôs as grandes potências ex-aliadas e aos dois Estados alemães realizar a reunificação mediante eleições livres. O plano soviético estabelecia que uma vez efetuada a reunificação, se procederia a retirada de todas as troas estrangeiras e a firma do tratado de paz. Em dito tratado se concederia a Alemanha o direito a contar com as forças necessárias para sua defesa e se lhe imporá a obrigação de não pertencer a nenhuma coalizão militar. A proposição soviética criava a possibilidade de resolver o problema da unidade alemã - assim admitiram muitos políticos ocidentais -, pero Adenauer se opôs tenazmente ao que foi condiderada. Depois do rearmamento da RFA e de sua entrada na OTAN, a 
reunificação se tornou praticamente impossível, pois a URSSA replico organizando o Tratado de Varsóvia ao que foi incorporada a RDA, que também formou seu próprio exército. (2008, p.362)

Três partidos comunistas emergem do KPD. O Partido Socialista Unificado da Alemanha (SED) na RDA, o KPD (até 1956) e o Partido Comunista Alemão (DKP) pós 1968 na RFA e o Partido Socialista Unificado de Betim Ocidental (PSUBO) sob a liderança de Horst Schimitt. Nas eleições na República Federal Alemã (RFA) o KPD participa e mesmo após mais de uma década de repressão obtém 1.361.076 votos (5,7\%) e 15 deputados (15/402). Já em 1953, após forte campanha anticomunista obtém 607.860 votos $(2,2 \%)$ não obtendo representação parlamentar. Em 1956, o Partido Comunista é novamente declarado ilegal. Em 1968, é fundado na Alemanha Ocidental o Partido Comunista Alemão (DKP).

Na República Democrática Alemã (RDA) após a libertação do território do fascismo hitlerista houve um processo de unificação do KPD e o SPD formando o Partido Socialista Unificado da Alemanha (SE). Entre 1950 e 1986 o Partido Socialista Unificado da Alemanha (SED) conformava junto com outros partidos a Frente Nacional, uma coalização política que governou a Alemanha Oriental entre 1950 e 1986. Nas eleições parlamentares oscilou entre onze e doze milhões de votos tendo cerca de um quarto dos/as deputados/as ${ }^{5}$, não chegando a obter em nenhum momento a maioria parlamentar. O historiador cubano Lezcano destaca a tensão entre os comunistas e os socialdemocratas na Alemanha Ocidental e nos informa que:

Embora Berlim Leste havia se convertido na capital da RDA, Berlim Ocidental foi transformado em um enclave da RFA dentro do território da RDA e utilizado contra ela, o que motivo a construção do famoso muro em agosto de 1961. A anormal situação de Berlim gerou um permanente foco de tensão entre as duas Alemanha e, desde logo, entre ambos blocos. No plano interno, Adenauer fomentou um clima de histeria anticomunista em que, antecipando-se em muitos anos a Ronald Reagan, se qualificava a URSS como o império do mal. Neste contexto, se perseguiu os comunistas, cujo partido foi finalmente ilegalizado em 1956, assim como os partidários da reunificação e a todos os que se opunham ao rearmamento alemão. Embora, foi se reabilitando paulatinamente os antigos Nazis, muitos dos quais chegaram a ocupar importantes posições na economia, no serviço exterior e no exército. Não é casual que em este período levantaram cabeça os seguidores da ideologia Nazi e formaram incluso seu próprio partido, o Nacional Democrata (PND). Há que se destacar que a Socialdemocracia, apesar de sua oposição ao regime de Adenauer, manteve uma atitude abertamente anticomunista, fazendo o jogo do velho chanceler (2008, p.363-364).

$\mathrm{Na}$ coluna intitulada Comunistas em luta pelo mundo é descrita a história do Partido Comunista Alemão (DKP) a partir da análise de Patrik Köbele, secretário geral do DKP7 , que sublinha a importância do processo de reconstituição do DKP, onde:

A palavra Reconstituição é muito importante e deve indicar que o DKP não é algo novo em relação ao então KPD (Partido Comunista da Alemanha) [...]. A linha da tradição é clara, não é coincidência. Na verdade, o processo de reconstituição começou mais cedo, com a tentativa muitas vezes suprimida pelos órgãos repressivos para apresentar o novo programa do KPD. E certamente um destaque foi a fundação da Juventude Socialista - SDAJ - em maio de 1968. 
Patrik Köbele, destaca resistência dos comunistas alemães em relação ao fenômeno do Eurocomunismo e às reformas defendidas por Gorbachov, destacando, entre outras coisas, que a "SDAJ e DKP se recusaram a segui-los". Ressalta também a participação ativa do DKP no Movimento de Paz independente da RDA e que a "influência da SDAJ e do DKP nas fábricas foi um fator real que se refletiu no desenvolvimento dos sindicatos. As batalhas tornaram-se mais políticas, os sindicatos representaram questões de propriedade (por exemplo, a socialização da indústria siderúrgica)". E que permanece os efeitos "da contrarrevolução bem-sucedida no socialismo na Europa" provocando uma crise permanente desde 89/90" que "em última análise, é uma crise do movimento dos trabalhadores, que também se perde na lógica da organização local e na cogestão, porque a parte revolucionária e comunista é pequena, fraca, desunida”. Finalmente os comunistas alemães apontam que “Os 200 anos de Karl Marx, 100 anos da Revolução de Outubro, 100 anos do KPD, 50 anos do DKP, são marcos históricos fundamentais que apontam para a reversão dessa situação”.

Cabe ressaltar a diferenciação entre o KPD e o DKP. O KPD tem 100 anos de história, enquanto o DKP 50 anos de reconstituição. O atual Partido Comunista Alemão (DKP) é a reconstituição do Partido Comunista da Alemanha (KPD), banido pelo Tribunal Constitucional da Alemanha Ocidental em 1956. Do lado oriental manteve relação com o Partido Socialista Unificado da Alemanha, hegemônico na República Democrática Alemã (RDA). Após a reunificação Alemã em 1990 o Partido Socialista Unificado da Alemanha (PSUA) transformou se no Partido do Socialismo Democrático da Alemanha (PDS) e depois no Partido da Esquerda (Die Linke), mantendo uma importante base eleitoral, política e social no Leste da Alemanha.

Na Alemanha o Partido Neonazista vem crescendo e se consolidando como a terceira força política nacional alemã. Na declaração do Partido Comunista o DKP avalia o resultado das eleições parlamentares alemã destacando uma "viragem à direita", onde segundo o DKP8:

A AfD é uma força racista e nacionalista, uma articulação para os abertamente fascistas, que se torna o terceiro maior partido no parlamento alemão, com 13\% dos votos válidos. É o partido mais forte da Saxônia e o segundo mais forte em toda a Alemanha Oriental. A CDU, o SPD, os Verdes e o Die Linke (A Esquerda) perderam eleitores para a AfD. Os 13\% dos votos recebidos pela AfD correlacionam-se aos resultados dos chamados estudos "Sinus", que desde a década de 1980 mostram que 13\% do eleitorado alemão (ocidental) tem uma "visão de mundo coerente com a direita". Acidentalmente ou não? De qualquer forma, o "submarino" chamado "nazifascismo", que na década de sessenta estava sob a forma do NPD (Partido Nacional Democrático da Alemanha), e que não se pode ignorar, emerge novamente.

O DKP após 1989 participou das últimas eleições para o Parlamento Alemão o Partido Comunista obteve somente 11.713 votos. Os Comunistas do DKP identificam e nomeiam "O capital monopolista como seu principal antagonista" destacando que "a mudança será alcançada na rua e não na urna". Destaca em seguida que "A solidariedade é o nosso trunfo - na greve, na prevenção de um impedimento nos bairros ou no bloqueio à manifestação neofascista. A solidariedade também é a nossa arma contra a AfD”. Percebe-se que as ações antifascistas estão 
presentes no plano de lutas atual do DKP e os comunistas alemães do DKP identificam a Alternativa para a Alemanha (AfD) como seu principal inimigo político. Trata-se de um partido neonazista com presença crescente no cenário político nacional alemão.

\section{Considerações finais}

A influência do pensamento e das contribuições teórico-práticas do leninismo na concepção de partido e nos traços programáticos destas organizações representou ao longo desta trajetória de mais de um século convergências políticas e divergências insuperáveis marcando uma rica experiência histórica que necessita ser revisitada. O renascimento do Movimento Comunista Internacional 30 anos após o fim da União das Repúblicas Socialistas Soviéticas (URSS) verificado a partir do processo de reorganização, refundação, fortalecimento e crescimento de diversos Partidos Comunistas comprovam a longevidade e atualidade do Marxismo-Leninismo.

A experiência histórica dos Comunistas Alemães e o desenvolvimento de sua política proletária devem ser investigados e reconsiderados no debate atual do Movimento Comunista Internacional. Devemos aprofundar às análises críticas, com base em novas referências bibliográficas e documentais, sobre a atuação da Internacional Comunista (1919-1943) e também questionar a ausência de uma Internacional Proletária vinculada aos partidos comunistas. Cem anos após a publicação da crítica de Lenin em relação aos comunistas “de esquerda", podemos afirmar que o Esquerdismo contribuiu para o enfraquecimento e a pulverização do Movimento Comunista Internacional, com o surgimento de várias outras organizações em sua grande maioria pequenos agrupamentos sectários com pouca duração, e no enfraquecimento do movimento operário sindical.

Por outro lado, as experiências de governos sociais democratas em aliança com partidos de centro-direita buscando humanizar o capitalismo em tempos de barbárie, de pandemia global e crise do capital mostram os limites históricos das ilusões reformistas abrindo novamente espaço para a ascensão da extrema-direita. Demonstrando que a crítica recorrente ao sectarismo dos comunistas alemães do KPD no período de ascensão do Nazismo, ignorando o anticomunismo promovido pela socialdemocracia alemã e o esquerdismo deve ser também reavaliada. Os comunistas alemães se reconstituíram em torno do Partido Comunista Alemão (DKP) e destacam que outros outubros e novembros virão!

\section{Referências:}

BADIA, Gilbert. Clara Zetkin: vida e obra. São Paulo: Expressão Popular, 2003.

BROUÉ, Pierre. História da Internacional Comunista (1919-1943); tradução de Fernando Ferrone. São Paulo: Sundermann, 2007.

LENIN, Vladimir. O esquerdismo doença infantil do comunismo. Moscou: Edições Progresso, 1986. 

Editorial Féliz Varela, 2008.

Artigos

MIES, Hebert. Não às tradições do imperialismo alemão. Revista Problemas, São Paulo, n¹3, p.47-56, abr/mai/jun-1985.

Os 50 anos do Partido Comunista Alemão. 2017. Disponível em: https://pcb.org.br/portal2/18075/os-50-anos-do-partido-comunista-alemao/. Acesso em 30 jun. 2020 .

PONOMARIOV, Boris. A transcendência internacional da vitória da URSS na Grande Guerra. Revista Problemas, São Paulo, n¹3, p.57-72. abr/mai/jun-1985.

SCHIMIT'T, Horst. O Partido de Lênin, partido da paz. Revista Problemas, São Paulo, nº1, p.3136, janeiro/março - 1986.

ZETKIN, Clara. Teses do Governo Operário. 1922. Tradução: Leonardo Godim. Disponível em: https:/ / lavrapalavra.com/2020/01/17/o-governo-dos-trabalhadores-teses-do-governo-operariosegundo-clara-zektin-e-a-iii-internacional/ . Acesso em 30 jun. 2020.

\footnotetext{
Notas

1 Historiador, Mestre em Educação pela Faculdade de Educação (FAE) da UFMG. Currículo Lattes: http://lattes.cnpq.br/0901143608835473. ORCID: $\quad$ http://dx.doi.org/10.9771/gmed.v12i2.37714. $\quad$ E-mail: ousarvencer@yahoo.com.br

2 Ernst Thälmann (1886-1944) foi um dirigente histórico do Partido Comunista da Alemanha (KPD). Thälmann participou da Liga Espartaquista, foi um dos fundadores do KPD e foi eleito seu secretário geral. Sob sua liderança o KPD se tornou a terceira força política social alemã. Thälmann mantinha relações estreitas com o Partido Comunista da União Soviética (PCUS). E, manteve profundas críticas ao Partido Social Democrata (SPD) chegando a caracteriza-los como "social-fascitas".

3 Clara Eisner Zetkin nasceu em 1857 na Alemanha e morreu em 20 de junho de 1933 em Moscou na União das Repúblicas Socialistas Soviéticas (U.R.S.S.). A partir de 1920, Clara Zetkin foi deputada no Reichstag, representando o Partido Comunista da Alemanha (KPD). Pierre Broué (2007, p. 1347) apresenta uma depreciativa definição biográfica de Clara Eisner Zetkin (1857-1933), como: "militante social-democrata, organizadora das mulheres socialistas, ligada à Rosa Luxemburgo. Junta-se ao KPD um pouco depois de sua formação, pertencendo nele constantemente à ala direita, apoiando Paul Levi e tentando impedir as expulsões dos "direitistas".

${ }^{4}$ Ernst Thälmann (1886-1944) foi um histórico líder comunista do Partido Comunista da Alemanhã (KPD). Thälman chegou a ser líder do braço armado do KPD o grupo Roter Frontkämpferbund proibido tanto pelo Governo SocialDemocrata como também pelos fascistas Alemães. Também participou da fundação em 1932 da Antifaschistische Aktion ou Antifa.

5 O SED obteve respectivamente a seguinte votação: 1950 - 12.088 .745 votos e 110 deputados (110/466); 1954 11.828.877 votos e 117 deputados (117/466); 1958 - 11.533.859 votos e 117 deputados (117/466); 1963 - 11.533 .859 votos e 110 deputados (110/434); 1967 - 11.197.265 votos e 110 deputados/as; 1971 - 11.207.388 votos e 110 deputados/as (110/434); 1976 - 11.245.023 votos e 110 deputados/as (110/434); 1981 - 12.235.515 votos e 127 deputados (127/500) e em 1986 - 12.392 .094 votos e 127 deputados/as $(127 / 500)$.

${ }^{6}$ Comunistas em luta pelo mundo (Secretaria de Relações Internacionais do PCB).

${ }^{7}$ O Partido Comunista Alemão - DKP - comemora, em 2018, seus 50 anos de fundação. Em artigo publicado na edição de 22 de dezembro de 2017, no jornal Unsere Zeit (Nosso Tempo), o Secretário Geral do DKP, Patrik Köbele, descreve a trajetória do Partido, afirmando que esta "Nunca foi fácil".

8 Declaração do Comitê Central do Partido Comunista Alemão (DKP) sobre as Eleições na Alemanha - Essen, Alemanha - 25/09/2017 - Traduções de Maria Helena De Eugênio para o Resistência.
}

Recebido em: 01.07.2020

Aprovado em: 25.08.2020 